\title{
Perceived Discrimination Is Associated with Binge Eating in a Community Sample of Non- Overweight, Overweight, and Obese Adults
}

\author{
Laura E. Durso $^{a} \quad$ Janet D. Latner ${ }^{b}$ Kentaro Hayashi ${ }^{b}$ \\ a The Williams Institute, UCLA School of Law, Los Angeles, CA, b Department of Psychology, \\ University of Hawai'i at Mānoa, Honolulu, HI, USA
}

\section{Key Words}

Discrimination $\cdot$ Binge eating $\cdot$ Obesity $\cdot$ Weight bias internalization

\begin{abstract}
Objective: The present study examined the relationship between experiences of discrimination and occurrence of binge eating among overweight and obese persons, a population which has previously shown elevated rates of binge eating. Methods: Internet-based questionnaires were used to measure frequency and impact of discrimination, binge eating frequency, and emotional eating. Results: Pearson correlation analyses demonstrated significant positive relationships between the measures of discrimination and measures of eating behaviors ( $r=0.12-0.37)$. Regression models significantly predicted between 17 and $33 \%$ of the variance of emotional eating scores and frequency of binge eating; discrimination measures contributed significantly and independently to the variance in emotional eating and binge eating. Weight bias internalization was found to be a partial mediator of the relationship between discrimination and eating disturbance. Conclusion: Results demonstrate the relationship of discrimination to binge eating. Weight bias internalization may be an important mechanism for this relationship and a potential treatment target.
\end{abstract}

Copyright $\odot 2012$ S. Karger GmbH, Freiburg

\section{Introduction}

Binge eating episodes, discrete periods of overeating characterized by the consumption of a large amount of food accompanied by a sense of loss of control over eating [1], are phenomena common to eating disorders as well as obesity. The prevalence of binge eating is particularly high among obese persons, with estimates of $20-46 \%$ in treatment-seeking populations [2] and 21\% in non-treatment-seeking populations [3]. Obese individuals with 
binge eating disorder (BED) are clinically distinct from obese persons who do not binge eat, with poorer self-esteem and health-related quality of life as well as greater body dissatisfaction, depressive symptoms, stress, and poorer physical health [3-10].

Risk factors for binge eating in BED and bulimia nervosa include dieting, negative selfevaluation, having obese parents, and facing persistent negative comments about weight and shape [11-14]. In particular, being bullied or teased in childhood, adolescence, or adulthood has been identified as a possible risk factor for binge eating [14]. Stress may also function as an antecedent to binge eating episodes $[15,16]$. Among women with a history of bulimia nervosa or BED, elevated levels of perceived stress experienced before the age of 14 preceded the onset of BEDs [17].

Experiencing discrimination can cause an individual significant stress [18] and as a result may have a negative impact on eating behavior. Recent research has shown that overweight and obese persons are more likely than their non-overweight counterparts to experience discrimination across a variety of domains [19-21]. Compared to non-obese persons, the overweight or obese are 40-50\% more likely to experience major discriminatory events [22]. The experience of weight-based discrimination is associated with greater depressive symptoms, general psychiatric symptoms, body image disturbance, and lower self-esteem $[23,24]$. Discrimination has also been associated with negative health outcomes, including elevated ambulatory blood pressure among adolescents reporting unfair treatment based on physical appearance [25], and higher physiological reactivity and slower physiological recovery following stress [26].

Given the high proportion of the overweight and obese population who experience binge eating episodes, discrimination may be among the factors associated with binge eating. Several authors have suggested that the increased rates of eating pathology seen in other stigmatized groups, such as gay men and lesbians, may be a method of coping with negative affect following discriminatory experiences [27-29]. Similarly, weight-based discrimination may be a specific form of stress that puts overweight and obese individuals at risk for episodes of binge eating. Emerging research suggests that weight-based discrimination may be associated with binge eating among obese adults enrolled in behavioral weight loss programs [30] and adults seeking weight loss surgery [31]. Recently, it has been shown that, among a sample of college students, weight stigmatization experiences independently contributed to the prediction of binge eating behaviors above other risk factors for binge eating, such as negative coping strategies, body dissatisfaction, and perceived stress [32]. Interestingly, the increased risk for binge eating found among undergraduates was not seen among a sample of adult bariatric surgery patients who faced weight-based discrimination. Despite this mixed picture, these findings suggest that perceived discrimination and weightbased stigma are related to the occurrence of binge eating among adults and point to the need for further research.

The internalization of negative beliefs about obesity by obese persons, known as internalized weight bias, may be associated with increased vulnerability to the negative psychological consequences of weight stigma [33]. Internalized weight bias was associated with body image concern, self-esteem, and binge eating among overweight and obese community men and women [34,35]. Obese women who endorse weight-based stereotypes report more frequent binge eating and refusal to diet in response to stigma experiences than those who do not endorse weight-based stereotypes [36]. Finally, among a sample of obese men and women seeking treatment for BED, internalized weight bias was shown to predict eating disorder psychopathology, as measured by the Eating Disorders Examination [37]. Given this evidence, the present study examined the internalization of weight bias as a partial mediator of the hypothesized relationship between discrimination and binge eating. 
The current study examined the relationship between discrimination and binge eating in a community sample of non-overweight, overweight, and obese adults. First, we predicted that experiences of both discrimination and binge eating would be higher among overweight and obese participants than among non-overweight participants. Second, we predicted that more experiences of discrimination would be associated with higher levels of binge eating, related eating disturbances, and emotional eating. Third, we predicted that discrimination would significantly and independently contribute to the variance in binge eating frequency above and beyond known risk factors for binge eating (i.e. perceived tress, parental obesity, childhood overweight, and childhood teasing). Fourth, we predicted that internalized weight bias would mediate the relationship between discrimination and binge eating.

\section{Participants and Methods}

\section{Participants and Procedures}

Participants over the age of 18 were recruited to complete an anonymous online survey (www.surveymonkey.com) [38]. Previous research supports the ability of the internet to provide adequately random samples [39]. Participants were recruited by email announcement to obesity-related discussion groups on www.yahoo.com and www.google.com, from websites on internet-based psychological research, and by colleagues of the researcher asked to forward the email announcement to their classes and social networks. These procedures were approved by the Institutional Review Board at the University of Hawai'i at Mānoa, and all participants gave consent to participate.

\section{Measures}

\section{Demographics}

All participants completed a demographics questionnaire created by the authors that asked for the participant's self-reported age, gender, height and weight (to calculate BMI ( $\left.\mathrm{kg} / \mathrm{m}^{2}\right)$ ), ethnicity, and weight status (from 'extremely underweight' to 'extremely overweight').

\section{Experiences of Discrimination}

Items from the National Survey of Midlife Development in the United States (MIDUS) were used to measure the frequency and impact of discrimination. These items have been widely used in large epidemiological studies investigating predictors and consequences of midlife development [40] and in previous research on discrimination against obese adults $[22,41]$. Items were selected from the survey that assess the cumulative frequency of major, institutionally based discriminatory events across a participant's lifetime (11 items, e.g., discrimination in job settings, harassment by the police), 9 items assessing perceived frequency of interpersonal, day-to-day occurrences of discrimination on a 4-point scale from 'never' to 'often' (e.g., being treated with less respect by others, receiving poorer service at stores or restaurants), and 2 items assessing the degree of impact that discrimination has had on each participant, on a 4-point scale from 'not at all' to 'a lot'. Frequency scores for the major discriminatory events, interpersonal discriminatory events, and discrimination impact were summed for each participant, forming three discrimination subscales, with higher scores indicating more discrimination.

\section{Risk Factors for Binge Eating}

Childhood overweight was measured by asking participants to classify their childhood weight status on a 7-point scale from 'extremely underweight' to 'extremely overweight.' Parental obesity was assessed using silhouettes from the Stunkard Figure Rating Scale [42] which asked participants to select the figure that most resembles their mother and father at their heaviest weight. Participants also completed the 22-item Perception of Teasing Scale (POTS) [43] which asked respondents to rate how often they experienced and were distressed by teasing behaviors from ages 5-16 (e.g., 'People made fun of you because you were heavy'). In the present sample, the POTS had a Cronbach's alpha of 0.85 for teasing frequency, 0.85 
for teasing distress, and 0.93 for the total scale. Perceived stress was measured using the Perceived Stress Scale (PSS) [44], a 14-item scale used to rate the frequency of stress-related thoughts and feelings on a scale from 'never' to 'very often' (sample item: 'In the last month, how often have you felt confident that you could handle your personal problems?') Cronbach's alpha of the PSS in the current sample was found to be 0.86 .

\section{Eating-Related Pathology}

The Eating Disorder Diagnostic Scale (EDDS) [45] is a 20 -item scale assessing frequency of binge eating and the diagnostic criteria for eating disorders. Two items, assessing frequency of binge eating over the past 3 months and over the past 6 months, were used in the present study. To gain additional information about the nature of participant's levels of eating pathology, the Drive for Thinness (DFT), Bulimia (BUL) and Body Dissatisfaction (BD) subscales of the Eating Disorder Inventory (EDI) [46] were administered. The DFT scale is a 7-item scale (from 'never' to 'always') that measures restrictive tendencies in eating and weight behaviors and cognitions (e.g., 'I am terrified of gaining weight'). The Bulimia subscale is a 7-item scale that measures the tendency towards overeating and purging behaviors (e.g., 'I have gone on eating binges where I have felt that I could not stop.'). Similarly, the BD subscale is a 9-item scale that assesses satisfaction with specific body parts, including the waist, hips and thighs (e.g., 'I think that my thighs are just the right size'). In the present sample, Cronbach's alphas were 0.91 (DFT and BUL) and 0.90 (BD).

\section{Emotional Eating}

As binge eating is a low base-rate behavior in the general, non-clinical population, the construct of emotional eating (the urge to eat following an emotional experience) was included to augment the diagnostic construct of binge eating. The Emotional Eating Scale (EES) [47] assesses the urge to eat following negative mood states by asking respondents to rate their desire from 'no desire to eat,' to 'an over whelming urge to eat' following the experience of 25 different emotions (e.g., 'sad,' 'frustrated'). In the present sample, Cronbach's alpha for the EES was 0.95.

\section{Weight Bias Internalization}

The Weight Bias Internalization Scale (WBIS) [35] assesses internalization of anti-fat bias in overweight and obese individuals. Respondents were asked to rate their agreement with 11 items on a 7-point scale from 'strongly disagree' to 'strongly agree' (e.g., 'I don't feel that I deserve to have a really fulfilling social life, as long as I'm overweight'). The 11-item WBIS had an internal consistency estimate of 0.82 in the present sample. As the WBIS is a relatively new measurement tool developed by the authors, scale refinement was conducted by calculating item-total correlations and removing items with correlations below 0.30 (two items). The resulting 9-item scale had a Cronbach's alpha of 0.86.

\section{Statistical Analysis}

Mean scores were calculated for all study measures, and Hotelling's $\mathrm{T}^{2}$ was used to test statistical differences between non-overweight and overweight/obese participants. Pearson product moment correlations were calculated across the full sample of participants to assess the relationship between measures of discrimination and measures of eating behavior. Hierarchical linear regression analyses were conducted to determine the relative contribution of each measure of discrimination to the prediction of emotional eating scores and binge eating frequency. Three models were tested using measures of emotional eating, 3-month binge eating frequency, or 6-month binge eating frequency as dependent variables. Block 1 included measures of previously established risk factors for binge eating - childhood weight status, parental weight status, POTS scores, and PSS scores [11-17]. Block 2 included all variables from Block 1 with the addition of each of the three measures of discrimination - frequency of institutional discrimination, frequency of interpersonal discrimination, and discrimination impact.

Finally, structural equation modeling (SEM) was used to test the fit of the mediation model presented in figure 1. The proposed model was fit to the data using Mplus version 5 (www.StatModel.com) [48]. Maximum likelihood estimation was employed to estimate the model parameters. The adequacy of the fit was determined using the comparative fit index (CFI), the standardized root mean square residual (SRMR), and the root mean square error of approximation (RMSEA). It has been suggested that a CFI above 0.90, an RMSEA less than 0.08 [49], and an SRMR less than 0.10 [50] represent an acceptable fit of the model. 
Fig. 1. SEM Model 1.0 representing the effect of perceived interpersonal discriminatory events and internalization of weight bias (WBIS) on the latent variable 'eating disturbance.' All paths represent standardized coefficients. * indicates the path is significant at $\mathrm{p}<0.01$. Latent variable components include EES, frequency of binge eating, BUL, DFT, and BD of the EDI.

Durso et al.: Perceived Discrimination Is Associated with Binge Eating in a Community Sample of Non-Overweight, Overweight, and Obese Adults

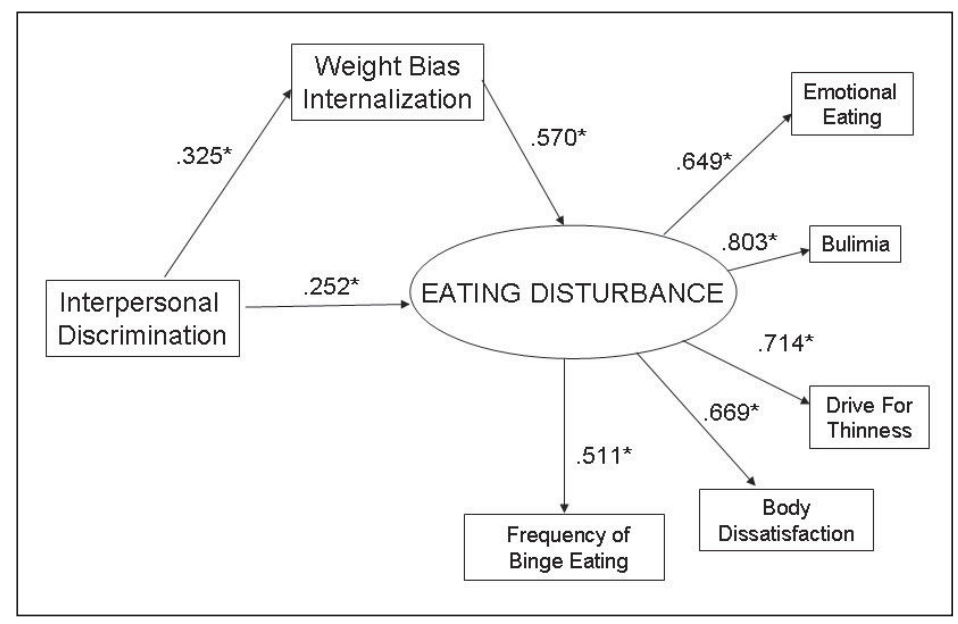

\section{Results}

\section{Participants}

In total, 486 persons accessed the online survey and, of those, 415 participants $(81.7 \%$ women; $40.2 \%$ non-overweight, $21.4 \%$ overweight, and $35.7 \%$ obese) provided height and weight data and could be included in the study. Participants included 79.5\% Caucasian, 5.3\% Asian/Pacific-Islander, 4.6\% Latina/o, 4.3\% of mixed ethnic heritage, 3.4\% African-American, and $0.7 \%$ Native American individuals. 34 individuals misclassified their weight status as being overweight even though their reported BMIs fell between 20 and $24.99 \mathrm{~kg} / \mathrm{m}^{2}$. These participants differed significantly from the group of accurately self-identified non-overweight participants on levels of perceived stress $(\mathrm{t}(139)=-3.67, \mathrm{p}<0.001)$, DFT $(\mathrm{t}(139)=-3.93, \mathrm{p}<$ $0.001)$ and $B D(t(139)=-5.36, p<0.001)$. To prevent the introduction of additional variability within each weight-status group, these 34 cases were excluded from analyses, yielding a final sample of 381 participants (non-overweight $n=153$; overweight/obese $n=228$ ).

\section{Group Differences}

Means and standard deviations for all study measures are presented in table 1 . The overall multivariate test was significant (Hotelling's $T^{2}=187.27 ; \mathrm{F}(1,218)=12.57, \mathrm{p}<0.001$ ), indicating differences between the non-overweight and overweight/obese groups. Tests of between-subjects effects demonstrate significant differences among the groups on all study measures except PSS scores. The overweight/obese group was found to have significantly higher mean scores on all measures of discrimination as well as the measures of emotional eating and eating-related pathology.

\section{Discrimination and Eating Disturbances}

Participants who had experienced at least one major discriminatory event reported greater EES scores $(\mathrm{t}(281)=3.14, \mathrm{p}=0.002)$ and higher mean BUL scores $(\mathrm{t}(266)=4.74, \mathrm{p}<$ 0.0001 ) than participants who had not experienced any major discriminatory event (not 
Table 1. Mean scores of all study measures - group comparison using Hotelling's $\mathrm{T}^{2}(\mathrm{n}=381)$

\begin{tabular}{lll}
\hline Measure & \multicolumn{2}{l}{ Mean (SD) } \\
\cline { 2 - 3 } & non-overweight & overweight \\
\hline Age, years (range = 18-76 years) & $29.75(9.14)$ & $39.06(11.45)^{* * *}$ \\
BMI, kg/m ${ }^{2}$ (range = 11.62-95.27 kg/m²) & $21.48(1.75)$ & $37.71(13.20)^{* * *}$ \\
EES & $1.94(0.77)$ & $2.45(0.89)^{* * *}$ \\
Binge eating frequency (3 months) & $0.64(1.79)$ & $2.46(4.06)^{* * *}$ \\
Binge eating frequency (6 months) & $0.55(1.05)$ & $1.72(2.00)^{* * *}$ \\
DFT & $2.83(1.41)$ & $3.38(1.28)^{* *}$ \\
Bulimia & $1.86(1.06)$ & $2.53(1.38)^{* * *}$ \\
BD & $3.14(0.94)$ & $4.54(1.21)^{* * *}$ \\
PSS & $1.80(0.56)$ & $1.96(0.62)$ \\
POTS frequency & $2.00(0.99)$ & $2.46(1.05)^{* * *}$ \\
POTS effect & $1.82(0.72)$ & $2.23(0.97)^{* * *}$ \\
Mother figure rating & $4.71(1.64)$ & $5.62(1.96)^{* *}$ \\
Father figure rating & $5.43(1.55)$ & $5.82(2.07)$ \\
Institutional discrimination & $2.25(3.02)$ & $6.78(9.96)^{* * *}$ \\
Interpersonal discrimination & $0.72(0.46)$ & $1.12(0.61)^{* * *}$ \\
Discrimination impact & $0.49(0.60)$ & $1.14(0.87)^{* * *}$ \\
\hline
\end{tabular}

${ }^{*} \mathrm{p}<0.05 .{ }^{* *} \mathrm{p}<0.01 .{ }^{* * *} \mathrm{p}<0.001$.

shown in table). Across the entire sample, both interpersonal discrimination and discrimination impact scores correlated significantly with EES scores, binge eating frequency, and BUL scores (range $r=0.19$ to $r=0.37$ ), as shown in table 2. Institutional discrimination scores correlated significantly with EES scores, 3-month binge eating frequency, and the BUL, but not with 6-month binge eating frequency.

\section{Predictors of Binge Eating and Emotional Eating}

For the sample as a whole, the hierarchical regression models predicted $33 \%$ of the variance in EES scores, $17 \%$ of the variance in 3-month binge eating frequency, and $19 \%$ of the 6-month binge eating frequency (table 3). For each dependent variable, the measures of discrimination added significantly to the variance in scores, over and above the proportion of variance accounted for by the previously established risk factors. Furthermore, interpersonal discrimination independently predicted 6-month binge eating frequency scores. Perceived stress was also a significant independent predictor of EES scores and 6-month binge eating frequency. Childhood weight status was found to be a significant predictor of 6-month binge eating frequency.

\section{Internalized Weight Bias as Mediator}

As interpersonal discrimination emerged as the strongest predictor of EES scores and binge eating frequency, this variable was included as the measure of discrimination experiences used for the mediation analysis. Of the two measures of binge eating frequency, frequency over the past 3 months was most strongly related to the measures of discrimination and was therefore included in the mediation analysis. Three-month binge eating 
Table 2. Correlation of discrimination measures with emotional eating and eating disturbance $(\mathrm{n}=381)$

\begin{tabular}{|c|c|c|c|c|c|c|c|}
\hline $\begin{array}{l}\text { Discrimination } \\
\text { measure }\end{array}$ & $\begin{array}{l}\text { Emotional } \\
\text { Eating Scale }\end{array}$ & $\begin{array}{l}\text { Binge eating } \\
\text { ( } 3 \text { months })\end{array}$ & $\begin{array}{l}\text { Binge eating } \\
\text { ( } 6 \text { months) }\end{array}$ & Bulimia & $\begin{array}{l}\text { Frequency } \\
\text { institutional } \\
\text { discrimination }\end{array}$ & $\begin{array}{l}\text { Frequency } \\
\text { interpersonal } \\
\text { discrimination }\end{array}$ & $\begin{array}{l}\text { Impact of } \\
\text { discrimination }\end{array}$ \\
\hline \multicolumn{8}{|c|}{ Pearson product-moment correlations } \\
\hline Institutional & $0.24^{* *}$ & $0.22^{* *}$ & 0.10 & $0.28^{* *}$ & - & - & - \\
\hline Interpersonal & $0.37^{* *}$ & $0.32^{* *}$ & $0.24^{* *}$ & $0.29 * *$ & $0.45^{* *}$ & - & - \\
\hline Impact & $0.32^{* *}$ & $0.28^{* *}$ & $0.19^{* *}$ & $0.29^{* *}$ & $0.50^{* *}$ & $0.69 * *$ & - \\
\hline \multicolumn{8}{|c|}{ Partial correlations controlling for age } \\
\hline Institutional & $0.24^{* *}$ & $0.15^{*}$ & 0.06 & $0.27^{* *}$ & - & - & - \\
\hline Interpersonal & $0.37^{* *}$ & $0.30^{* * *}$ & $0.26^{* *}$ & $0.30^{* *}$ & $0.43^{* *}$ & - & - \\
\hline Impact & $0.31^{* *}$ & $0.24^{* *}$ & $0.19^{* *}$ & $0.27^{* *}$ & $0.50^{* *}$ & $0.69^{* *}$ & - \\
\hline \multicolumn{8}{|c|}{ Partial correlations controlling for BMI } \\
\hline Institutional & $0.18^{* *}$ & 0.08 & -0.04 & $0.20^{* *}$ & - & - & - \\
\hline Interpersonal & $0.31^{* *}$ & $0.21^{* *}$ & $0.17^{* *}$ & $0.22^{* *}$ & $0.37^{* *}$ & - & - \\
\hline Impact & $0.26^{* *}$ & $0.16^{* *}$ & 0.11 & $0.20^{* *}$ & $0.43^{* *}$ & $0.64^{* *}$ & - \\
\hline \multicolumn{8}{|c|}{ Partial correlations controlling for perceived stress scores } \\
\hline Institutional & $0.24^{* *}$ & $0.19^{* *}$ & 0.08 & $0.25^{* *}$ & - & - & - \\
\hline Interpersonal & $0.25^{* *}$ & $0.25^{* *}$ & $0.17^{* *}$ & $0.19^{* *}$ & $0.42^{* *}$ & - & - \\
\hline Impact & $0.19^{* *}$ & $0.21^{* *}$ & $0.12^{*}$ & $0.19^{* *}$ & $0.47^{* *}$ & $0.68^{* *}$ & - \\
\hline
\end{tabular}

${ }^{*} \mathrm{p}<0.05 .{ }^{* *} \mathrm{p}<0.01$.

frequency was combined with the other study measures relating to eating behavior (EES as well as BUL, DFT, and BD) to create the latent variable 'eating disturbance' to be tested using SEM. Exploratory factor analysis conducted using the SPSS Statistical Software package (SPSS, Chicago, IL, USA) using maximum likelihood estimation with a Promax rotation confirmed that these variables could be represented as a single factor. Component extraction was set for one factor. Factor loadings for each item as well as visual analysis of the Scree plot demonstrated that the items could be represented by a single factor (Eigenvalue $=3.03$ ). The final SEM model was used to test the impact of WBIS scores on the relationship between perceived discrimination and the latent variable 'eating disturbance'. As only overweight and obese participants completed the WBIS, this analysis included just overweight and obese participants.

The majority of the fit statistics suggested that the model was an adequate fit to the data $(\mathrm{CFI}=0.92, \mathrm{SRMR}=0.05$, and RMSEA $=0.111)$ and all path coefficients were significant $(\mathrm{p}<$ 0.01 ). The model explained $45 \%$ of the variance of the latent variable 'eating disturbance.' The total statistical effect of discrimination on eating disturbance was calculated by multiplying the standardized path coefficients from discrimination to internalization and from internalization to eating disturbance (i.e. the indirect effects); the product was then added to the direct effect of discrimination on eating disturbance. The total statistical effect of discrimination on eating disturbance was calculated to be 0.44 . Using the method outlined by Sobel [51, 52], path coefficients and their standard errors were used to calculate the significance of the total effect. The total effect of discrimination on eating disturbance was found to be significant $(t=4.71, p<0.01)$. The acceptable fit of the model to the data indicates that internalization of weight bias partially mediates the relationship between discrimination and eating disturbance among overweight and obese participants. 
Table 3. Summary of multiple regression analyses $(n=381)$

\begin{tabular}{|c|c|c|}
\hline Predictor variables & $\triangle \mathrm{R}^{2}$ & $\beta$ \\
\hline \multicolumn{3}{|l|}{ Emotional Eating Scale } \\
\hline Step 1 & 0.29 & \\
\hline Childhood weight & & 0.06 \\
\hline Father figure & & 0.08 \\
\hline Mother figure & & -0.05 \\
\hline POTS frequency & & -0.01 \\
\hline POTS effect & & 0.17 \\
\hline PSS & & $0.36^{* *}$ \\
\hline Step 2 & & 0.03 \\
\hline Institutional discrimination & & 0.10 \\
\hline Interpersonal discrimination & & 15 \\
\hline Discrimination impact & & 0.00 \\
\hline Total $\mathrm{R}^{2}$ & $0.33^{* *}$ & \\
\hline \multicolumn{3}{|c|}{ Binge eating frequency (past 3 months) } \\
\hline Step 1 & 0.11 & \\
\hline Childhood weight & & 0.04 \\
\hline Father figure & & -0.05 \\
\hline Mother figure & & -0.07 \\
\hline POTS frequency & & -0.05 \\
\hline POTS effect & & 0.12 \\
\hline PSS & & 0.14 \\
\hline Step 2 & 0.06 & \\
\hline Institutional discrimination & & 0.05 \\
\hline Interpersonal discrimination & & 0.17 \\
\hline Discrimination impact & & 0.09 \\
\hline Total $\mathrm{R}^{2}$ & $0.17^{* *}$ & \\
\hline \multicolumn{3}{|c|}{ Binge eating frequency (past 6 months) } \\
\hline Step 1 & 0.15 & \\
\hline Childhood weight & & $0.17^{*}$ \\
\hline Father figure & & -0.06 \\
\hline Mother figure & & -0.11 \\
\hline POTS frequency & & -0.14 \\
\hline POTS effect & & 0.13 \\
\hline PSS & & $0.19^{* *}$ \\
\hline Step 2 & 0.04 & \\
\hline Institutional discrimination & & -0.05 \\
\hline Interpersonal discrimination & & $0.21^{*}$ \\
\hline Discrimination impact & & 0.07 \\
\hline Total $\mathrm{R}^{2}$ & $0.19^{* *}$ & \\
\hline
\end{tabular}

Father figure $=$ Paternal silhouette from the Questionnaire on Eating and Weight Patterns; Mother figure $=$ maternal silhouette from the Questionnaire on Eating and Weight Patterns.

${ }^{*} \mathrm{p}<0.05 .{ }^{* *} \mathrm{p}<0.01 .{ }^{* *} \mathrm{p}<0.001$.

\section{Discussion}

The present results suggest that perceived discrimination, from subtle day-to-day experiences to significant life events, is associated with eating disturbance. Participants who reported more frequent experiences of discrimination were also more likely to report more frequent bulimic behaviors, binge eating episodes, and a greater tendency to overeat in 
response to changes in affect. The present findings are consistent with past research demonstrating an association between overweight and eating disturbance (e.g., [11, 12, 53]). However, the present results remained significant when controlling for BMI, demonstrating that discrimination is associated with dysfunctional eating behavior irrespective of body weight.

The current study also showed that measures of discrimination, along with previously identified risk factors for binge eating (childhood weight status, parental weight status, history of teasing, and perceived stress), accounted for 17-33\% of the variance in scores of eating disturbance. SEM demonstrated that, among overweight and obese participants, $45 \%$ of the variance in eating disturbance was accounted for by interpersonal discrimination. Internalization of weight bias was a partial mediator of the relationship between discrimination and eating disturbance.

Interpersonal discrimination emerged as the type of discrimination most strongly associated with eating disturbances, even when taking into account known risk factors. This result suggests that events of seemingly lower severity (e.g., being treated with less courtesy) may be more closely related to well-being than events of seemingly higher severity (e.g., not being given a job promotion). Persons facing such types of subtle interpersonal discrimination may have few strategies to combat or respond to these events, relative to the legal recourse available in cases such as police harassment or job discrimination [54, 55]. These results are consistent with previous findings that perceived daily stress predicts binge eating [17]. Though cross-sectional in nature, these data suggest that day-to-day discrimination is a specific stressor that may be associated with eating disturbance over and above the effects of other daily life stressors.

The correlational design is an important limitation of the present study, as causal inferences cannot be drawn about the relationship between the study variables. The methodology used to test the theoretical relationship between perceived discrimination, internalized weight bias, and eating disturbance (e.g., SEM) utilizes the correlations among constructs, and these results require replication, ideally with time-series data, before firmer conclusions can be stated. Another important limitation is the use of an online sample of self-selected participants, who may be systematically different from participants who choose to complete paper-and-pencil questionnaires or who would not self-select into a study of experiences of discrimination and eating behaviors. In addition, though the correlation coefficients found in this study were low, there remains the possibility of common method bias, and future research should utilize multi-method designs to assess these constructs. Further research in this area should also use prospective, experimental, and quasi-experimental designs to describe the mechanisms behind the relationship between discrimination and binge eating and address the current study's limitations. Given previous findings that the experience of stress may be greater for individuals with bulimia nervosa $[15,16,56]$, it is possible that reporting of discrimination could be inflated among individuals who binge eat. In addition, participant age may a potential confound of the results, since the overweight/obese group was significantly older than the non-overweight group. It is reasonable to suspect that the longer one has lived, the more discrimination one has faced and the accumulation of both discriminatory experience and weight gain over time could potentially contribute to the relationship between discrimination and eating disturbance. However, partial correlations controlling for the impact of participant age and BMI demonstrated that the relationship between the perception of discrimination and eating behaviors remains strong even when these variables are taken into account.

The results of this study suggest that binge eating treatment protocols should consider clients' histories of discrimination and stigmatization. It may be important to assist overweight clients in interpreting discriminatory actions as byproducts of stereotypes and bias 
and not as legitimate events which the client somehow 'deserves' [23, 57]. Internalized weight bias, as a mediator of the relationship between discrimination and eating disturbance, may be another important therapeutic target. Future research should examine whether internalization of weight bias is associated with additional health outcomes, such as healthcare utilization, or the health consequences commonly observed among overweight and obese individuals [58]. Reducing the negative psychosocial outcomes of discrimination may not only improve an individual's quality of life but might also remove impediments to seeking treatments $[36,59]$. Finally, the current study highlights the importance of interpersonal discriminatory experiences and developing strategies that target and reduce these events. A two-pronged approach to treatment and prevention, targeting the negative effects of discrimination at the individual level and reducing discrimination in the larger social context, may have the greatest and longest lasting impact on the health and well-being of overweight and obese persons.

\section{Disclosure Statement}

The authors note no conflicts of interest.

\section{References}

1 American Psychiatric Association: Diagnostic and Statistical Manual of Mental Disorders, 4th ed. Washington, DC, American Psychiatric Association, 1994.

2 Marcus MD, Wing RR: Binge eating among the obese. Ann Behav Med 1987;9:23-27.

- 3 French SA, Jeffery RW, Sherwood NE, Neumark-Sztainer D: Prevalence and correlates of binge eating in a nonclinical sample of women enrolled in a weight gain prevention program. Int J Obes 1999;23:576-585.

4 Striegel-Moore RH, Wilson GT, Wilfley DE, Elder KA, Brownell KD: Binge eating in an obese community sample. Int J Eat Disord 1998;23:27-37.

5 Masheb RM, Grilo CM: Quality of life in patients with binge eating disorder. Eat Weight Disord 2004;9:194199.

- 6 Rieger E, Wilfley DE, Stein RI, Marino V, Crow SJ: A comparison of quality of life in obese individuals with and without binge eating disorder. Int J Eat Disord 2005;37:234-240.

- 7 Gluck ME, Geliebter A, Hung J, Yahav E: Cortisol, hunger, and desire to binge eating following a cold stress test in obese women with binge eating disorder. Psychosom Med 2004;66:876-881.

- 8 Gluck ME, Geliebter A, Lorence M: Cortisol stress response is positively correlated with central obesity in obese women with binge eating disorder (BED) before and after cognitive-behavioral treatment. Ann N Y Acad Sci 2004;1032:202-207.

- 9 Friederich HC, Schild S, Schellberg D, Quenter A, Bode C, Herzog W, Zipfel S: Cardiac parasympathetic regulation in obese women with binge eating disorder. Int J Obes 2006;30:534-542.

10 Bulik CM, Sullivan PF, Kendler KS: Medical and psychiatric morbidity in obese women with and without binge eating disorder. Int J Eat Disord 2002;32:72-78.

11 Fairburn CG, Doll HA, Welch SL, Hay PJ, Davies BA, O’Connor ME: Risk factors for binge eating disorder: a community-based, case-control study. Arch Gen Psychiatry 1998;55:425-432.

12 Fairburn CG, Welch SL, Doll HA, Davies BA: Risk factors for bulimia nervosa: a community-based casecontrol study. Arch Gen Psychiatry 1997;54:509-517.

13 Jackson TD, Grilo CM, Masheb RM: Teasing history, onset of obesity, current eating disorder psychopathology, body dissatisfaction, and psychological functioning in binge eating disorder. Obes Res 2000;8: 451-458.

-14 Striegel-Moore RH, Dohm F, Pike KM, Wilfley DE, Fairburn CG: Abuse, bullying, and discrimination as risk factors for binge eating disorder. Am J Psychiatry 2002;159:1902-1907.

15 Bennett DA, Cooper CL: Eating disturbance as a manifestation of the stress process: a review of the literature. Stress Med 1999;15:167-182.

-16 Freeman LMY, Gill KM: Daily stress, coping and dietary restraint in binge eating. Int J Eat Disord 2004;36: 204-212.

-17 Striegel-Moore RH, Dohm F, Kraemer HC, Schreiber GB, Taylor CB, Daniels SR: Risk factors for binge eating disorders: an exploratory study. Int J Eat Disord 2007;40:481-487. 
Durso et al.: Perceived Discrimination Is Associated with Binge Eating in a

Community Sample of Non-Overweight, Overweight, and Obese Adults

18 Allison KW: Stress and oppressed social category membership; in Swim JK, Stangor C (eds): Prejudice: The Target's Perspective. San Diego, Academic Press, 1998, pp 145-170.

19 Myers A, Rosen JC: Obesity stigmatization and coping: relation to mental health symptoms, body image, and self-esteem. Int J Obes 1999;23:221-230.

20 Puhl R, Brownell KD: Bias, discrimination, and obesity. Obes Res 2001;9:788-805.

21 Puhl R, Heuer CA: The stigma of obesity: a review and update. Obesity (Silver Spring) 2009;17:941-964.

-22 Carr D, Friedman MA: Is obesity stigmatizing? Body weight, perceived discrimination, and psychological well-being in the United States. J Health Soc Behav 2005;46:244-259.

-23 Crocker J, Cornwell B, Major B: The stigma of overweight: affective consequences of attributional ambiguity. J Per Soc Psychol 1993;64: 60-70.

-24 Friedman KE, Reichmann SK, Costanzo PR, Zelli A, Ashmore JA, Musante GJ: Weight stigmatization and ideological beliefs: relation to psychological functioning in obese adults. Obes Res 2005;13:907-916.

25 Matthews KA, Salomon K, Kenyon K, Zhou F: Unfair treatment, discrimination, and ambulatory blood pressure in black and white adolescents. Health Psychol 2005;24:258-265.

-26 Richman LS, Bennett GG, Pek J, Siegler I, Williams RB: Discrimination, dispositions, and cardiovascular responses to stress. Health Psychol 2007;26:675-683.

27 Heffernan K: Eating disorders and weight concern among lesbians. Int J Eat Disord 1996;19:127-138.

28 Meyer C, Blissett J, Oldfield C: Sexual orientation and eating pathology: the role of masculinity and femininity. Int J Eat Disord 2001;29:314-318.

29 Yancey AK, Cochran SD, Corliss HL, Mays VM: Correlates of overweight and obesity among lesbian and bisexual women. Prev Med 2003;36:676-683.

-30 AshmoreJA, Friedman KE, Reichmann SK, Musante GJ: Weight-based stigmatization, psychological distress, and binge eating behavior among obese treatment-seeking adults. Eat Behav 2008;9:203-209.

-31 Friedman KE, Ashmore JA, Applegate KL: Recent experiences of weight-based stigmatization in a weight loss surgery population: psychological and behavioral correlates. Obesity (Silver Spring) 2008;16(suppl 2):S69-S74.

-32 Almeida L, Savoy S, Boxer P: The role of weight stigmatization in cumulative risk for binge eating. J Clin Psychol 2011;67:278-292.

33 Quinn DM, Crocker J: Vulnerability to the affective consequences of the stigma of overweight; in Swim JK, Stangor C (eds): Prejudice: The Target's Perspective. San Diego, Academic Press, 1998, pp 125-143.

-34 Carels RA, Wott CB, Young KM, Gumble A, Koball A, Oehlhof MW: Implicit, explicit and internalized weight bias and psychosocial maladjustment among treatment-seeking adults. Eat Behav 2010;11:180-185.

-35 Durso LE, Latner JD: Understanding self-directed stigma: development of the weight bias internalization scale. Obesity (Silver Spring) 2008;16(suppl 2):S80-S86.

-36 Puhl R, Moss-Racusin CA, Schwartz MB: Internalization of weight bias: implications for binge eating and emotional well-being. Obes Res 2007;15:19-23.

-37 Durso LE, Latner JD, White MA, Masheb RM, Blomquist KK, Morgan PT, Grilo CM: Internalized weight bias in obese patients with binge eating disorder: associations with eating disturbances and psychological functioning. Int J Eat Disord 2012;45:423-427.

-38 Gordon A: SurveyMonkey.com - web-based survey and evaluation system http://www.SurveyMonkey. com. Internet Higher Educ 2002;5:83-87.

-39 Gosling SD, Vazire S, Srivastava S, John OP: Should we trust web-based studies? A comparative analysis of six preconceptions about internet questionnaires. Am Psychol 2004;59:93-104.

40 Brim OG, Baltes PB, Bumpass LL, Cleary PD, Featherman DL, Hazzard WR, Kessler RC, Lachman MC, Markus HR, Marmot MG, Rossi, AS, Ryff CD, Shweder RA: National Survey of Midlife Development in the United States (MIDUS), 1995-1996 (Computer file). 2nd ICPSR version. Ann Arbor, DataStat, Inc./Boston, Harvard Medical School, Dept. of Health Care Policy (producers), 1996. Ann Arbor, Inter-university Consortium for Political and Social Research (distributor), 2003.

-41 Puhl R, Andreyeva T, Brownell KD: Perceptions of weight discrimination: prevalence and comparison to race and gender discrimination in America. Int J Obes 2008;32:992-1000.

42 Stunkard AJ, Sorensen T, Schulsinger F: Use of the Danish Adoption Register for the study of obesity and thinness; in Kety SS, Rowland LP, Sidman SW, Mathysee SW (eds): The Genetics of Neurological and Psychiatric Disorders New York, Raven Press, 1983, pp 115-120.

43 Thompson JK, Cattarin J, Fowler B, Fisher E: The perception of teasing scale (POTS): a revision and extension of the physical appearance related teasing scale (PARTS). J Pers Assess 1995;65:146-157.

44 Cohen S, Kamark T, Mermelstein R: A global measure of perceived stress. J Health Soc Behav 1983;24:385396.

-45 Stice E, Telch CF, Rizvi SL: Development and validation of the eating disorder diagnostic scale: a brief selfreport measure of anorexia, bulimia and binge eating disorder. Psychol Assess 2000;12:123-131.

-46 Garner DM, Olmsted MP, Polivy J: The development and validation of a multidimensional eating disorder inventory for anorexia nervosa and bulimia. Int J Eat Disord 1983;2:15-34.

47 Arnow B, Kenardy J, Agras WS: The emotional eating scale: the development of a measure to assess coping with negative affect by eating. Int J Eat Disord 1995;18: 79-90.

48 Muthen LK, Muthen BO: Mplus User's Guide. Los Angeles, Muthen \& Muthen, 1998. 
49 Byrne BM: Structural Equation Modeling with AMOS: Basic Concepts, Applications, and Programming. Mahwah, Lawrence Erlbaum Associates, 2001.

50 Browne MW, Cudeck R: Alternative ways of assessing model fit. in Bollen KA, Long S. (eds): Testing Structural Equation Models Newbury Park, Sage, 1993, pp 136-162.

51 Sobel MF: Asymptotic confidence intervals for indirect effects in structural equation models. Sociol Methodol 1982;12:290-312.

52 Sobel MF: Some new results on indirect effects and their standard errors in covariance structure models. Sociol Methodol 1986;16:159-186.

53 Spitzer RL, Yanovski SZ, Wadden TA, Marcus MD, Stunkard AJ, Devlin M: Binge eating disorder: its further validation in a multisite study. Int J Eat Disord 1993;13:137-153.

54 Puhl R, Brownell KD: Ways of coping with obesity stigma: review and conceptual analysis. Eat Behav 2003; 4:53-78.

-55 Puhl R, Brownell KD: Confronting and coping with weight stigma: an investigation of overweight and obese adults. Obesity (Silver Spring) 2006;14:1802-1815.

56 Crowther JH, Sanftner J, Bonifazi DZ, Shepherd KL: The role of daily hassles in binge eating. Int J Eat Disord 2001;29:449-454.

57 Crocker J, Major B: Social stigma and self-esteem: the self-protective properties of stigma. Psychol Rev 1989;96:608-630.

58 National Heart Lung and Blood Institute: LHLBI Clinical Guidelines on the Identification, Evaluation, and Treatment of Overweight and Obesity in Adults. The Evidence Report. Obes Res 1998;6(suppl 2):51S-209S.

59 Ciao AC, Latner JD, Durso LE: Treatment seeking and barriers to weight loss treatments of different intensity levels among obese and overweight individuals. Eat Weight Disord 2012;17:e9-16. 